Article

\title{
Degradation Mechanism of 2,4-Dichlorophenol by Fungi Isolated from Marine Invertebrates
}

\author{
Efstratios Nikolaivits ${ }^{1} \oplus$, Andreas Agrafiotis ${ }^{1}$, Eirini Baira ${ }^{2}$, Géraldine Le Goff ${ }^{3}$, \\ Nikolaos Tsafantakis ${ }^{2}$, Suchana A. Chavanich ${ }^{4}$, Yehuda Benayahu ${ }^{5}$, Jamal Ouazzani ${ }^{3}{ }^{(D)}$, \\ Nikolas Fokialakis 2 (D) and Evangelos Topakas 1,6,*(D)
}

1 Industrial Biotechnology \& Biocatalysis Group, Biotechnology Laboratory, School of Chemical Engineering, National Technical University of Athens, 15780 Athens, Greece; snikolai@central.ntua.gr (E.N.); agrafiotisandreas.vep@gmail.com (A.A.)

2 Division of Pharmacognosy and Chemistry of Natural Products, Department of Pharmacy, National and Kapodistrian University of Athens, 15771 Athens, Greece; ebaira@pharm.uoa.gr (E.B.); ntsafantakis@pharm.uoa.gr (N.T.); fokialakis@pharm.uoa.gr (N.F.)

3 Institut de Chimie des Substances Naturelles, ICSN, CNRS, 91198 Gif sur Yvette, France; geraldine.legoff@cnrs.fr (G.L.G.); jamal.ouazzani@cnrs.fr (J.O.)

4 Faculty of Science, Chulalongkorn University, Bangkok 10330, Thailand; suchana.c@chula.ac.th

5 School of Zoology, Faculty of Life Sciences, Tel Aviv University, Tel Aviv 69978, Israel; YehudaB@tauex.tau.ac.il

6 Biochemical and Chemical Process Engineering, Division of Sustainable Process Engineering, Department of Civil, Environmental and Natural Resources Engineering, Luleå University of Technology, SE-97187 Luleå, Sweden

* Correspondence: vtopakas@chemeng.ntua.gr; Tel.: +30-210-772-3264

Received: 14 April 2020; Accepted: 4 May 2020; Published: 7 May 2020

\begin{abstract}
Dichlorophenol (2,4-DCP) is a ubiquitous environmental pollutant categorized as a priority pollutant by the United States (US) Environmental Protection Agency, posing adverse health effects on humans and wildlife. Bioremediation is proposed as an eco-friendly, cost-effective alternative to traditional physicochemical remediation techniques. In the present study, fungal strains were isolated from marine invertebrates and tested for their ability to biotransform 2,4-DCP at a concentration of $1 \mathrm{mM}$. The most competent strains were studied further for the expression of catechol dioxygenase activities and the produced metabolites. One strain, identified as Tritirachium sp., expressed high levels of extracellular catechol 1,2-dioxygenase activity. The same strain also produced a dechlorinated cleavage product of the starting compound, indicating the assimilation of the xenobiotic by the fungus. This work also enriches the knowledge about the mechanisms employed by marine-derived fungi in order to defend themselves against chlorinated xenobiotics.
\end{abstract}

Keywords: 2,4-dichlorophenol; marine-derived fungi; invertebrate symbionts; catechol dioxygenase; DCP metabolites

\section{Introduction}

The progress of industrialization and increase in various human activities increased the use of various chemicals in various consumer products, drugs, pesticides, food additives, fuels, and industrial solvents. Pollution of air, water, and soil can occur as a result of the improper disposal of said chemicals [1]. There is recently heightened concern among policymakers and scientists with regard to the effects of human and wildlife exposure to chemical compounds in the environment, particularly the aquatic environment [2]. Application of pesticides, insecticides, and herbicides constitutes the main source of water pollution with phenolic compounds through an agricultural source. 
The treatment of pollutants performed via conventional methods (both physical and chemical) is a costly, time-consuming approach that generates other contaminants in the process [3]. According to an assessment, restoring of contaminated sites in the United States of America (USA) requires a capital investment of ca. \$1.7 trillion United States dollars (USD). Hence, bioremediation emerged as a safe, low-cost, and environmentally friendly alternative technology to achieve sustainable removal of hazardous pollutants [1]. The US Environmental Protection Agency (USEPA) defines bioremediation as a treatment process in which microorganisms are employed to degrade or modify toxic pollutants to less harmful products, thus reducing environmental pollutants generated by various anthropogenic activities.

Phenolic pollutants are recalcitrant to biodegradation, due to their aromatic structure that is hard to cleave. The first step toward the degradation of such pollutants is usually their hydroxylation performed by monooxygenases [4], leading to catecholic derivatives (catechol, protocatechuate, or hydroxyquinol), which are subsequently transformed by ring-cleaving dioxygenases. The cleavage of the ring is a very important step toward the mineralization of the molecule and is performed by inserting two oxygen atoms of molecular oxygen either between (ortho cleavage) or beside (meta cleavage) the two hydroxyl groups of the ring [5]. Intradiol dioxygenases (ortho pathway) are $\mathrm{Fe}^{3+}$-containing enzymes, while extradiol dioxygenases (meta pathway) contain an $\mathrm{Fe}^{2+}$ center for catalysis [6]. Extradiol dioxygenases also include the cupin-type dioxygenases, which act on noncatecholic hydroxy-substituted aromatic carboxylic acids (gentisate, salicylate, 1-hydroxy-2-naphthoate, or aminohydroxybenzoates) [7].

The marine environment is an untapped source of microbial diversity, showing various characteristics valuable for biotechnological applications, including bioremediation [8]. Marine and estuarine environments are repositories of numerous organic pollutants, such as petroleum hydrocarbons, chlorinated and brominated organics, plastics, etc. The halogenated organics have natural sources; thus, marine environments naturally harbor a great microbial diversity for the degradation of those types of organic compounds, which are involved in a microbial degradation network [9]. Fungi are robust organisms, and most of them are usually more tolerant to high concentrations of pollutants compared to bacteria; hence, they are more efficient in bioremediation compared to other microorganisms [10].

The present work describes the screening of 27 fungal strains isolated from three different marine ecosystems as symbionts of different invertebrates (such as sponges, corals, tunicates, and bivalves) from the east Mediterranean Sea, Red Sea, and Andaman Sea. In order to enrich the catalog of biocatalysts able to convert chlorinated aromatic pollutants, these strains were screened for their degradation potential of 2,4-dichlorophenol (2,4-DCP), which was considered as a model di-halogenated aromatic compound.

\section{Results and Discussion}

\subsection{Biotransformation Potential of 2,4-DCP by Marine-Derived Fungi}

In our previous work [11], we studied the bioremediation potential of symbiotic fungal strains deriving from different depths (30-152 m) of the mesophotic marine zone (upper, middle, and lower). In the present work, invertebrates collected from the east Mediterranean Sea and the Red Sea were found in the upper mesophotic zone (35-49 m), while those from the Andaman Sea were found from shallow reefs $(6-15 \mathrm{~m})$. Additionally, the collection of invertebrates took place in different time periods in each case. The microorganisms were isolated as invertebrate symbionts and cultivated in marine broth, in order to maintain the salinity of the medium. The non-mesophotic isolates were dominated by Penicillium (54\%) and Aspergillus (31\%) species. Mesophotic strains were more diverse, being represented mostly by Aspergillus (29\%), Penicillium (21\%), and Aphanoascus (21\%) species.

Most of the 27 isolates screened showed significant 2,4-DCP bioconversion potential. The decrease in 2,4-DCP concentration at the end of the resting-cell incubation (10 days) is presented in Table 1. 
The overall average removal yield was $33 \%$, and it was the same for the mesophotic and non-mesophotic strains. The majority of strains (74\%) could transform 2,4-DCP at yields between $20 \%$ and $50 \%$. In our previous study [11], again, the majority of marine-derived strains reached removal yields between $20 \%$ and $50 \%$, and the overall average was similar (32\%). Out of the 27 strains in this study, only four were able to reach bioconversion yields over 55\%, namely, Cladosporium sp. ML6-S1 (64.0\%), Aspergillus sp. ML147-S2 (55.1\%), Penicillium chrysogenum ML156-S8 (59.5\%), and Tritirachium sp. ML197-S3 (66.3\%). These strains seem to be different from those studied in our previous work, such as Penicillium steckii, Chrysosporium sp., Penicillium sp., Aspergillus creber, and Aspergillus sp. The initial concentration of 2,4-DCP used $\left(163 \mathrm{mg} \cdot \mathrm{mL}^{-1}\right)$ is higher than most reported so far. Concentrations of $40-100 \mathrm{mg} \cdot \mathrm{mL}^{-1}$ were tested by various researchers, and the removal yields were between $20 \%$ and $65 \%$ [12-15].

Table 1. Percentage of 2,4-dichlorophenol (2,4-DCP) removal in resting-cell reactions after 10 days for all isolated fungal strains, which were identified based on their internal transcribed spacer (ITS) sequence. Information (region and depth) about the invertebrate host of each strain is given. Locations: Red Sea (Red), east Mediterranean Sea (Med E), and Andaman Sea (Andaman).

\begin{tabular}{|c|c|c|c|c|c|}
\hline Isolate & Invertebrate & Location & Depth (m) & Isolate Identification & $\begin{array}{c}\% \text { DCP } \\
\text { Removal }\end{array}$ \\
\hline ML119-S1 & Bivalve (Pteria aegyptiaca) & Red & 35 & Aphanoascus fulvescens & 25.4 \\
\hline ML132-S1 & Amphimedon ochracea & Red & 35 & Aspergillus fumigatus & 27.3 \\
\hline ML133-S2 & Soft coral (Sarcophyton glaucum) & Red & 35 & Cladosporium halotolerans & 9.3 \\
\hline ML136-S2 & Bivalve (Pteria aegyptiaca) & Red & 35 & Aspergillus sp. (fumigatus) & 41.4 \\
\hline ML149-S1 & Sarcotragus muscarum & Med E & 49 & Aphanoascus fulvescens & 41.8 \\
\hline ML150-S1 & Sarcotragus muscarum & Med E & 45 & Aphanoascus fulvescens & 35.8 \\
\hline ML153-S1 & Sarcotragus muscarum & Med E & 45 & Penicillium fellutanum & 13.9 \\
\hline ML153-S2 & Sarcotragus muscarum & Med E & 45 & Penicillium fellutanum & 24.7 \\
\hline ML155-S1 & Sarcotragus muscarum & Med E & 35 & Lecanicillium sp. & 19.0 \\
\hline ML14-S1 & Sponge (Phobas arborescens) & Andaman & $10-15$ & Aspergillus niger & 22.9 \\
\hline ML15-S1 & Sponge (Phobas arborescens) & Andaman & $10-15$ & Aspergillus terreus & 27.3 \\
\hline ML16-S2 & Sponge (Iotrochota baculifera) & Andaman & $10-15$ & Penicillium chrysogenum & 37.9 \\
\hline ML45-S3 & Hydroid (Macrorhynchia philippina) & Andaman & $10-15$ & Penicillium chrysogenum & 27.1 \\
\hline ML45-S5 & Hydroid (Macrorhynchia philippina) & Andaman & $10-15$ & Penicillium steckii & 36.3 \\
\hline ML45-S6 & Hydroid (Macrorhynchia philippina) & Andaman & $10-15$ & Purpureocillium lilacinum & 32.8 \\
\hline ML52-S1 & Unknown hydroid & Andaman & $10-15$ & Penicillium citrinum & 26.7 \\
\hline ML52-S5 & Unknown hydroid & Andaman & $10-15$ & Penicillium coffeae & 26.8 \\
\hline ML52-S6 & Unknown hydroid & Andaman & $10-15$ & Aspergillus niger & 29.3 \\
\hline ML52-S7 & Unknown hydroid & Andaman & $10-15$ & Penicillium steckii & 31.7 \\
\hline ML52-S8 & Unknown hydroid & Andaman & $10-15$ & Aspergillus fumigatus & 32.8 \\
\hline
\end{tabular}

\subsection{Expression of Catechol Dioxygenase Activities}

Extracellular catechol dioxygenase activities were measured in the culture broth of the tested strains following induction with 2,4-DCP. All tested strains seemed to mostly express catechol 1,2-dioxygenase (C12O) instead of catechol 2,3-dioxygenase (C23O) activity. C23O activity is expressed in very low levels, and just two strains-Tritirachium sp. ML197-S3 and Aspergillus sp. ML147-S2-presented detectable activity at $63 \mathrm{~h}$ of 0.36 and $0.33 \mathrm{U} \cdot \mathrm{mg}^{-1}$, respectively. As seen in Figure 1, the majority of strains, except for Aspergillus sp. ML147-S2, presented the maximum $\mathrm{C} 12 \mathrm{O}$ activity at $63 \mathrm{~h}$. Additionally, it is clear that the strain Tritirachium sp. ML197-S3 had the ability to express high C12O activity (41.50 $\mathrm{U} \cdot \mathrm{mg}^{-1}$ ) compared to the rest of the tested strains, being 28-fold higher than the second highest strain (Cladosporium sp. ML6-S1). Intracellular C12O activity of the strain Tritirachium sp. ML197-S3 was also measured at the peak point of extracellular activity. While the activity detected in the extracellular medium was found to be $0.55 \mathrm{U}$, the intracellular one was $0.13 \mathrm{U}$, which constitutes only $19 \%$ of the total $\mathrm{C} 12 \mathrm{O}$ activity detected. Aspergillus awamori NRRL 3112, which had the ability to grow on several 
phenolic compounds, expressed $0.043 \mathrm{U} \cdot \mathrm{mg}^{-1}$ of extracellular $\mathrm{C} 12 \mathrm{O}$ when grown on 2,4-DCP [16]. The same strain, when grown on phenol and catechol, expressed higher specific $\mathrm{C} 12 \mathrm{O}$ activity both intra- and extracellularly.

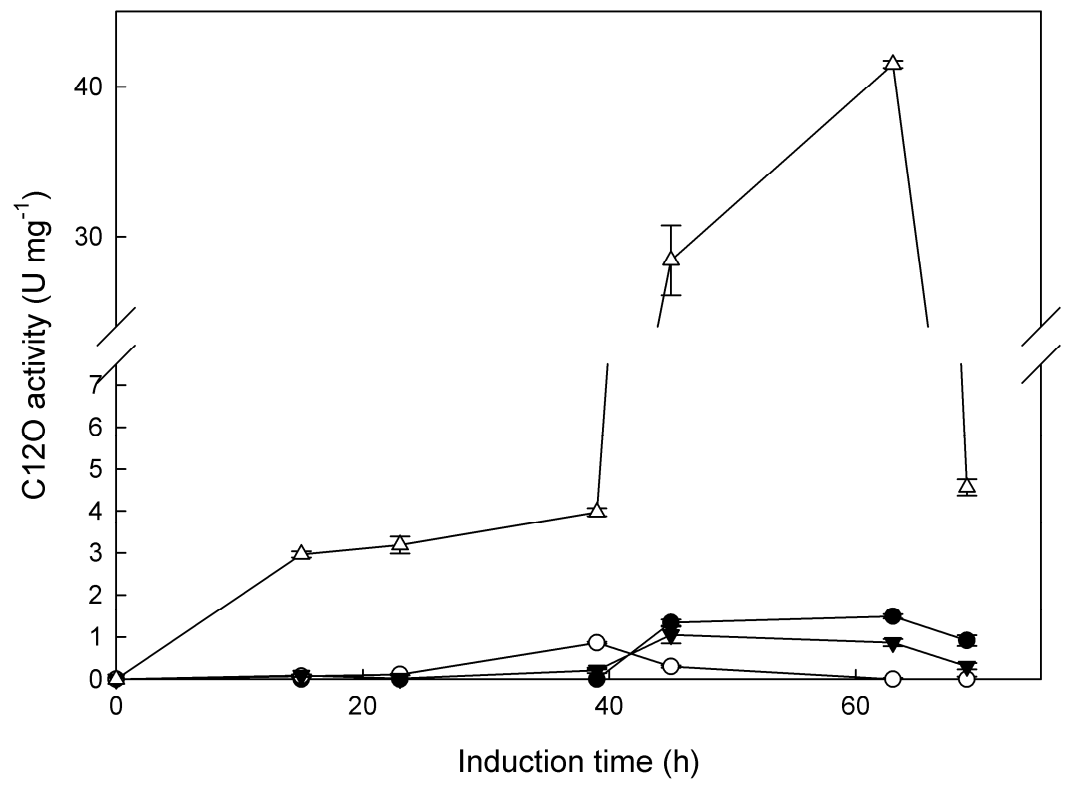

Figure 1. Time-course of the extracellular catechol 1,2-dioxygenase (C12O) activity expressed as U.mg ${ }^{-1}$ of protein for the four selected strains, induced by $1 \mathrm{mM}$ 2,4-DCP. Strains: Cladosporium sp. ML6-S1 (•),

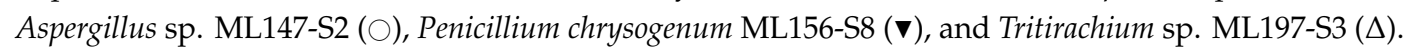

Bacterial intradiol dioxygenases were extensively investigated regarding their reaction mechanism, substrate specificity, and structures [5]. C12O enzymes are known to be expressed by various microorganisms able to degrade phenolic pollutants. Bacteria able to assimilate 3-hydroxybenzoate [17], phenol [18], benzoic acid [19], and $\alpha$-naphthol [20] express such enzymes that were characterized. On the contrary, the reports about $\mathrm{C} 12 \mathrm{O}$ expression by fungi, mostly related to their biochemical characterization, are scarce. Phenol-induced $\mathrm{C} 12 \mathrm{O}$ activity was detected in various filamentous fungi [21,22], and only a few reports on isolation and characterization from Candida strains were published [23,24].

\subsection{Identification of 2,4-DCP Metabolites}

The bacterial mechanisms for the detoxification and assimilation of chlorophenols are well known and were reviewed recently [25]. On the other hand, the studies regarding the defensive mechanisms of fungi for the handling of chlorophenols and especially 2,4-DCP are limited. In general, fungi are known to utilize a two-step process for the detoxification of xenobiotics. During phase I, they express enzymes, typically belonging to the cytochrome P450 family, which modify the initial compound by adding functional groups, such as $-\mathrm{OH}$. The resulting compounds are then further modified by phase II enzymes that include several non-specific transferases (sulfo-, glycosyl-, glutathione-, etc.). Their products are less toxic and are excreted from the cells without any further modification [26,27].

Based on the MS analysis, several compounds were detected. However, the emphasis was given to compounds related to the 2,4-DCP metabolism study. For the annotation of 2,4-DCP metabolites, various software tools and online databases were employed. For the prediction of the elemental composition (EC) of the compounds, software tools such as Sirius, Rdisop, and mMass were employed according to the accurate mass, the relative intensities of the first and second isotopes of each compound, the composition rules of H/C, NOPS/C, and Ring Double Bond Equivalent value (RDBE), and applying an $\mathrm{m} / \mathrm{z}$ tolerance of $10 \mathrm{ppm}$. The online databases Metlin and Chemspider, as well as data from literature, were used to annotate the metabolites with an applied $\mathrm{m} / \mathrm{z}$ tolerance of $10 \mathrm{ppm}$. All the 
compounds that are characterized as metabolites were only detected on DCP-treated cell cultures. Table 2 depicts the 2,4-DCP metabolites based on the analysis.

Table 2. 2,4-DCP metabolites traced only in DCP-treated cell cultures. Rt = retention time; $(\mathrm{M}-\mathrm{H})^{-}=$ $\mathrm{m} / \mathrm{z}$ of the pseudomolecular ion; $\mathrm{EC}=$ the elemental composition.

\begin{tabular}{|c|c|c|c|c|}
\hline A/A & Rt (min) & $(\mathbf{M}-\mathbf{H})^{-}$ & EC & Found In \\
\hline (1) & 0.89 & 126.9987 & $\mathrm{C}_{6} \mathrm{H}_{5} \mathrm{ClO}$ & Aspergillus sp. MLm147-S2 \\
\hline (2) & 1.11 & 157.0146 & $\mathrm{C}_{6} \mathrm{H}_{6} \mathrm{O}_{5}$ & Tritirachium sp. MLm197-S3 \\
\hline (3) & 1.45 & 287.0449 & $\mathrm{C}_{11} \mathrm{H}_{13} \mathrm{O}_{5} \mathrm{~N}_{2} \mathrm{Cl}$ & Tritirachium sp. MLm197-S3 \\
\hline (3) & 1.47 & 287.0452 & $\mathrm{C}_{11} \mathrm{H}_{13} \mathrm{O}_{5} \mathrm{~N}_{2} \mathrm{Cl}$ & $\begin{array}{l}\text { Tritirachium sp. MLm197-S3, } \\
\text { Aspergillus sp. MLm147-S2 }\end{array}$ \\
\hline (3) & 1.50 & 287.0452 & $\mathrm{C}_{11} \mathrm{H}_{13} \mathrm{O}_{5} \mathrm{~N}_{2} \mathrm{Cl}$ & P. chrysogenum MLm156-S8 \\
\hline (4) & 2.33 & 141.0197 & $\mathrm{C}_{6} \mathrm{H}_{6} \mathrm{O}_{4}$ & Tritirachium sp. MLm197-S3 \\
\hline (4) & 2.44 & 141.0196 & $\mathrm{C}_{6} \mathrm{H}_{6} \mathrm{O}_{4}$ & P. chrysogenum MLm156-S8 \\
\hline (4) & 2.45 & 141.0196 & $\mathrm{C}_{6} \mathrm{H}_{6} \mathrm{O}_{4}$ & Cladosporium sp. MLm6-S1 \\
\hline (4) & 2.46 & 141.0196 & $\mathrm{C}_{6} \mathrm{H}_{6} \mathrm{O}_{4}$ & Cladosporium sp. MLm6-S1 \\
\hline (4) & 2.50 & 141.0196 & $\mathrm{C}_{6} \mathrm{H}_{6} \mathrm{O}_{4}$ & Cladosporium sp. MLm6-S1 \\
\hline (5) & 3.15 & 125.0248 & $\mathrm{C}_{6} \mathrm{H}_{6} \mathrm{O}_{3}$ & Aspergillus sp. MLm147-S2 \\
\hline (5) & 3.18 & 125.0249 & $\mathrm{C}_{6} \mathrm{H}_{6} \mathrm{O}_{3}$ & Aspergillus sp. MLm147-S2 \\
\hline (5) & 3.19 & 125.0248 & $\mathrm{C}_{6} \mathrm{H}_{6} \mathrm{O}_{3}$ & Tritirachium sp. MLm197-S3 \\
\hline (5) & 3.19 & 125.0248 & $\mathrm{C}_{6} \mathrm{H}_{6} \mathrm{O}_{3}$ & Cladosporium sp. MLm6-S1 \\
\hline (5) & 3.20 & 125.0247 & $\mathrm{C}_{6} \mathrm{H}_{6} \mathrm{O}_{3}$ & Cladosporium sp. MLm6-S1 \\
\hline (5) & 3.20 & 125.0248 & $\mathrm{C}_{6} \mathrm{H}_{6} \mathrm{O}_{3}$ & P. chrysogenum MLm156-S8 \\
\hline (5) & 3.22 & 125.0248 & $\mathrm{C}_{6} \mathrm{H}_{6} \mathrm{O}_{3}$ & Tritirachium sp. MLm197-S3 \\
\hline (5) & 3.22 & 125.0248 & $\mathrm{C}_{6} \mathrm{H}_{6} \mathrm{O}_{3}$ & Cladosporium sp. MLm6-S1 \\
\hline (5) & 3.23 & 125.0250 & $\mathrm{C}_{6} \mathrm{H}_{6} \mathrm{O}_{3}$ & P. chrysogenum MLm156-S8 \\
\hline (5) & 3.25 & 125.0249 & $\mathrm{C}_{6} \mathrm{H}_{6} \mathrm{O}_{3}$ & Aspergillus sp. MLm147-S2 \\
\hline (5) & 3.27 & 125.0250 & $\mathrm{C}_{6} \mathrm{H}_{6} \mathrm{O}_{3}$ & Tritirachium sp. MLm197-S3 \\
\hline (5) & 3.27 & 125.0251 & $\mathrm{C}_{6} \mathrm{H}_{6} \mathrm{O}_{3}$ & P. chrysogenum MLm156-S8 \\
\hline (6) & 6.93 & 245.9994 & $\mathrm{C}_{9} \mathrm{H}_{10} \mathrm{NClO} 3 \mathrm{~S}$ & Cladosporium sp. MLm6-S1 \\
\hline (7) & 7.34 & 206.9523 & $\mathrm{C}_{6} \mathrm{H}_{5} \mathrm{O}_{4} \mathrm{ClS}$ & Aspergillus sp. MLm147-S2 \\
\hline (8) & 10.62 & 339.0041 & $\mathrm{C}_{12} \mathrm{H}_{14} \mathrm{Cl}_{2} \mathrm{O}_{7}$ & Tritirachium sp. MLm197-S3 \\
\hline (8) & 10.62 & 339.0042 & $\mathrm{C}_{12} \mathrm{H}_{14} \mathrm{Cl}_{2} \mathrm{O}_{7}$ & Aspergillus sp. MLm147-S2 \\
\hline (8) & 10.64 & 339.0040 & $\mathrm{C}_{12} \mathrm{H}_{14} \mathrm{Cl}_{2} \mathrm{O}_{7}$ & Tritirachium sp. MLm197-S3 \\
\hline (8) & 10.73 & 339.0041 & $\mathrm{C}_{12} \mathrm{H}_{14} \mathrm{Cl}_{2} \mathrm{O}_{7}$ & Aspergillus sp. MLm147-S2 \\
\hline (9) & 11.91 & 176.9517 & $\mathrm{Cl}_{2} \mathrm{C}_{6} \mathrm{H}_{2}(\mathrm{OH})_{2}$ & Cladosporium sp. MLm6-S1 \\
\hline (9) & 11.92 & 176.9517 & $\mathrm{Cl}_{2} \mathrm{C}_{6} \mathrm{H}_{2}(\mathrm{OH})_{2}$ & Aspergillus sp. MLm147-S2 \\
\hline (9) & 11.93 & 176.9518 & $\mathrm{C}_{6} \mathrm{H}_{4} \mathrm{Cl}_{2} \mathrm{O}_{2}$ & P. chrysogenum MLm156-S8 \\
\hline (9) & 11.94 & 176.9517 & $\mathrm{C}_{6} \mathrm{H}_{4} \mathrm{Cl}_{2} \mathrm{O}_{2}$ & Tritirachium sp. MLm197-S3 \\
\hline (9) & 11.94 & 176.9517 & $\mathrm{Cl}_{2} \mathrm{C}_{6} \mathrm{H}_{2}(\mathrm{OH})_{2}$ & Cladosporium sp. MLm6-S1 \\
\hline (9) & 11.96 & 176.9521 & $\mathrm{C}_{6} \mathrm{H}_{4} \mathrm{Cl}_{2} \mathrm{O}_{2}$ & P. chrysogenum MLm156-S8 \\
\hline (9) & 11.96 & 176.9521 & $\mathrm{C}_{6} \mathrm{H}_{4} \mathrm{Cl}_{2} \mathrm{O}_{2}$ & Tritirachium sp. MLm197-S3 \\
\hline (9) & 12 & 176.9521 & $\mathrm{C}_{6} \mathrm{H}_{4} \mathrm{Cl}_{2} \mathrm{O}_{2}$ & P. chrysogenum MLm156-S8 \\
\hline$(10)$ & 13.46 & 160.9572 & $\mathrm{C}_{6} \mathrm{H}_{4} \mathrm{Cl}_{2} \mathrm{O}$ & Aspergillus sp. MLm147-S2 \\
\hline (10) & 13.46 & 160.9571 & $\mathrm{C}_{6} \mathrm{H}_{4} \mathrm{Cl}_{2} \mathrm{O}$ & Control day 10 \\
\hline (10) & 13.47 & 160.9571 & $\mathrm{C}_{6} \mathrm{H}_{4} \mathrm{Cl}_{2} \mathrm{O}$ & Tritirachium sp. MLm197-S3 \\
\hline (10) & 13.48 & 160.9572 & $\mathrm{C}_{6} \mathrm{H}_{4} \mathrm{Cl}_{2} \mathrm{O}$ & Aspergillus sp. MLm147-S2 \\
\hline (10) & 13.48 & 160.9572 & $\mathrm{C}_{6} \mathrm{H}_{4} \mathrm{Cl}_{2} \mathrm{O}$ & Cladosporium sp. MLm6-S1 \\
\hline$(10)$ & 13.48 & 160.9572 & $\mathrm{C}_{6} \mathrm{H}_{4} \mathrm{Cl}_{2} \mathrm{O}$ & P. chrysogenum MLm156-S8 \\
\hline (10) & 13.49 & 160.9572 & $\mathrm{C}_{6} \mathrm{H}_{4} \mathrm{Cl}_{2} \mathrm{O}$ & Cladosporium sp. MLm6-S1 \\
\hline (10) & 13.50 & 160.9573 & $\mathrm{C}_{6} \mathrm{H}_{4} \mathrm{Cl}_{2} \mathrm{O}$ & P. chrysogenum MLm156-S8 \\
\hline$(10)$ & 13.50 & 160.9571 & $\mathrm{C}_{6} \mathrm{H}_{4} \mathrm{Cl}_{2} \mathrm{O}$ & P. chrysogenum MLm156-S8 \\
\hline (10) & 13.51 & 160.9571 & $\mathrm{C}_{6} \mathrm{H}_{4} \mathrm{Cl}_{2} \mathrm{O}$ & Tritirachium sp. MLm197-S3 \\
\hline (10) & 13.51 & 160.9572 & $\mathrm{C}_{6} \mathrm{H}_{4} \mathrm{Cl}_{2} \mathrm{O}$ & Tritirachium sp. MLm197-S3 \\
\hline (10) & 13.52 & 160.9572 & $\mathrm{C}_{6} \mathrm{H}_{4} \mathrm{Cl}_{2} \mathrm{O}$ & Control day 6 \\
\hline$(10)$ & 13.52 & 160.9573 & $\mathrm{C}_{6} \mathrm{H}_{4} \mathrm{Cl}_{2} \mathrm{O}$ & Aspergillus sp. MLm147-S2 \\
\hline$(10)$ & 13.53 & 160.9572 & $\mathrm{C}_{6} \mathrm{H}_{4} \mathrm{Cl}_{2} \mathrm{O}$ & Cladosporium sp. MLm6-S1 \\
\hline$(10)$ & 13.55 & 160.9572 & $\mathrm{C}_{6} \mathrm{H}_{4} \mathrm{Cl}_{2} \mathrm{O}$ & Control day 2 \\
\hline
\end{tabular}


Nine metabolites of 2,4 DCP (10) were identified, where some are still holding a chlorine substituent. For Aspergillus sp. ML147-S2 and Tritirachium sp. ML197-S3, six metabolites were detected, while, for the remaining two strains, only four metabolites were detected. All of the tested strains were able to hydroxylate 2,4-DCP to generate an ortho diol (9), which is appropriate for further dioxygenase reactivity $[25,28]$. All of the selected strains are able to substitute the two chlorines of 2,4-DCP by hydroxyl groups leading to trihydroxybenzene (or hydroxyquinol) (5). All strains except for Aspergillus sp. ML147-S2 were able to transform compound (9) into tetrahydroxybenzene (4). The aforementioned reactions are performed by phase I enzymes mostly cytochrome-P450 monooxygenases. This intense dechlorination capacity of the selected strains revealed a specific detoxification activity proportionally related to the number of chlorines on the aromatic ring. The further glycosylation of (9) to (8) by Aspergillus sp. ML147-S2 and Tritirachium sp. ML197-S3 is aimed at enhancing compound removal from the cells as the final step of detoxification. Finally, except for Cladosporium sp. ML6-S1, all the strains were able to convert compound (9) to the corresponding glutamine conjugate (3). Complete dechlorination of the starting xenobiotic is really important, since it substantially decreases its toxicity. However, there was also a non-dechlorinated product of dichlorocatechol in a glycosylated form (8). This metabolite was found in strains Aspergillus sp. ML147-S2 and Tritirachium sp. ML197-S3, and, even though it is much less lipophilic than its precursor, it still contains both chlorine atoms and it is probably a dead-end product. Dichlorocatechol could also be partially dechlorinated by all strains, except for Cladosporium sp. ML6-S1, to form the respective glutamine conjugate (3).

Other partially dechlorinated products were also detected, such as chlorophenol (1) in Aspergillus sp. ML147-S2 and sulfated (7) and cysteine (6) conjugates in Aspergillus sp. ML147-S2 and Cladosporium sp. ML6-S1.

In the reaction of Tritirachium sp. ML197-S3, based on HRMS data, 2-hydroxymuconic acid (2) was detected. This compound may derive from a dioxygenase catalyzed cleavage of (5). This could be correlated to the high $\mathrm{C} 12 \mathrm{O}$ activity detected in this strain. This is a very significant finding, since there is a high probability of 2,4-DCP being assimilated by this particular strain. However, this result is in contrast to the degradation mechanism of 2,4-DCP by bacteria, where the cleavage of the ring is performed before the dehalogenation of the compound [29].

\subsection{Metabolic Pathways of 2,4-DCP}

As previously reported with exclusively mesophotic fungi [11], dioxygenase activities were found in addition to no cleavage products. However, hydroxyquinol was detected, which was the only fully dechlorinated metabolite. Despite that, the metabolites of mesophotic fungi were more diverse compared to the fungi in the present study. However, several compounds were detected in both cases, such as dichlorocatechol, its glycoside, and its glutamine conjugate, as well as chlorophenol and its sulfated and cysteine conjugates. The isolated Aspergillus strains from the two studies, Aspergillus sp. ML147-S2, Aspergillus creber TM122-S3, and Aspergillus sp. TM124-S1, had only two metabolites in common: sulfated chlorophenol and the glutamine conjugate of chlorocatechol. On the other hand, Penicillium chrysogenum ML156-S8 had only one common metabolite with Penicillium sp. TM38-S1 [11].

Other than that, little is known about the 2,4-DCP metabolites of other fungi. Soil fungus Mortierella sp. used two different pathways for the detoxification of 2,4-DCP. The first included its hydroxylation to dichlorocatechol similar to the present study and its further methylation to dichloroguaiacol, while the second involved its oxidative dechlorination to 2-chloro-hydroquinone and its further reductive dehalogenation to hydroquinone [28]. Some of the metabolites of 2,4-DCP by white-rot fungus Phanerochaete chrysosporium were also identified to be 2,4-dichloroanisole, 2-chloro-1,4-hydroquinone, and 2-chloro-1,4-dimethoxybenzene [30]. P. chrysosporium was also able to completely dechlorinate the starting compound, yielding 2,5-dimethoxy-1,4-hydroquinone and 1,2,4,5-tetrahydroxybenzene.

Based on literature data and MS results presented in Table 2, the metabolic pathway utilized by the investigated fungal strains for the detoxification of 2,4-DCP was envisaged. Structural configurations 
presented in Figure 2 are tentative and are based on the most probable conformation according to the compound dynamics and data reported in literature.

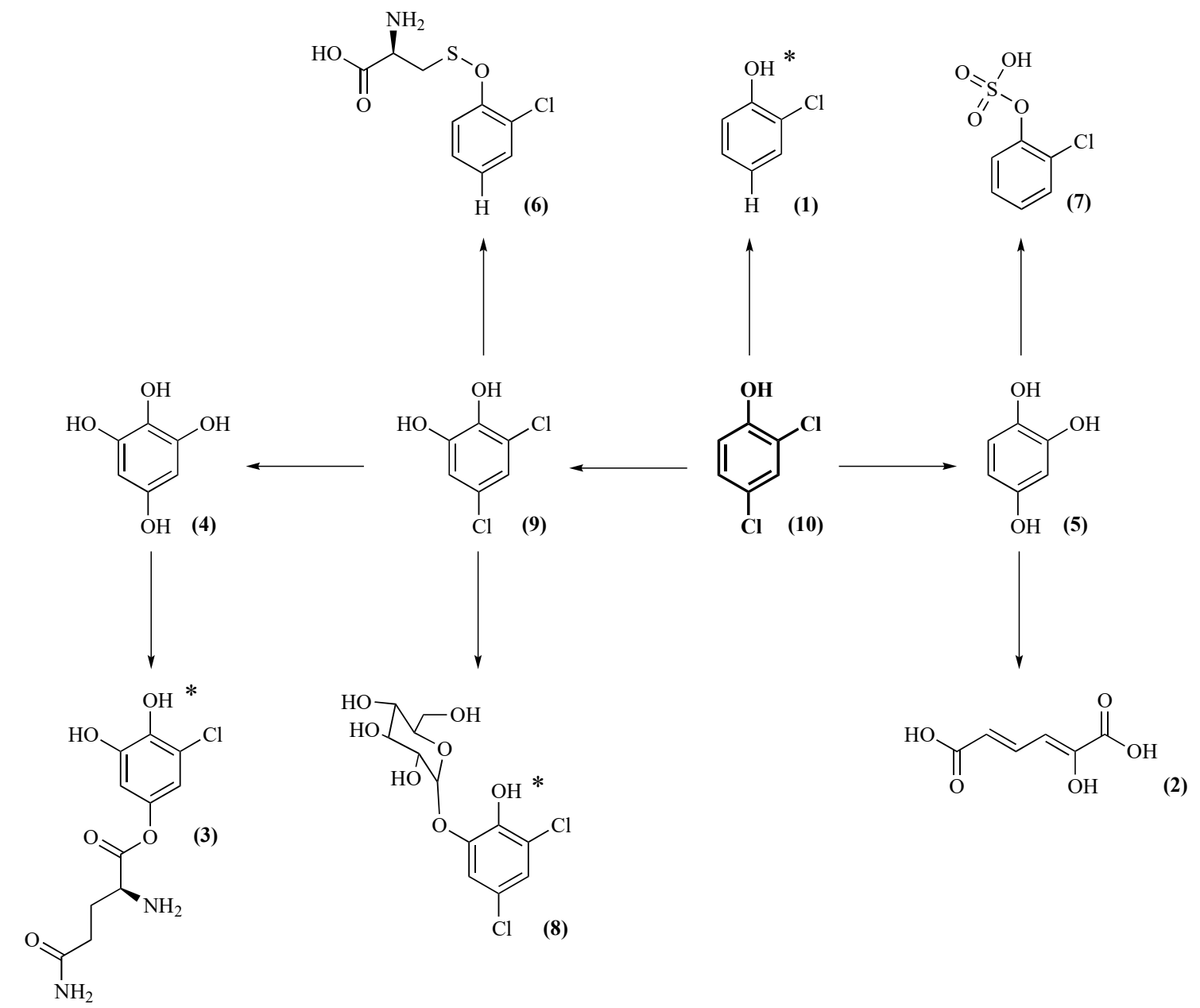

Figure 2. Proposed metabolic pathway for the detoxification of 2,4-DCP by the isolated fungi. The isomers were suggested according to MS and literature data. For the metabolites where there is no information about the most probable isomer, an asterisk was added next to the molecule. The number next to each compound is that corresponding to Table 2.

The biotransformation yield of 2,4-DCP by the studied isolates cannot be directly correlated with the metabolites detected. Undoubtedly, catechol dioxygenase activities and the presence of a ring cleavage product are very important factors that probably enhance the overall biotransformation yield; however, they are not the only ones. As seen with the identified metabolites, different enzymes take part in the initial 2,4-DCP transformation. When other enzymes can act on these initial metabolites, then the first enzymes can presumably act even more on 2,4-DCP. What is also important is the formation of compounds that can be further processed by the microbial metabolism and not just dead-end products. Definitely, the overall biotransformation yield is not as crucial as the quality of the produced metabolites and, more specifically, their dichlorination process, since our main goal is the detoxification of the starting pollutant.

\section{Materials and Methods}

\subsection{Chemicals}

2,4-Dichlorophenol (99\%) was purchased from Sigma-Aldrich (St. Louis, MO, USA). Organic solvents (acetonitrile and chloroform) were of HPLC grade (Fisher Chemical, Pittsburgh, PA, USA). 


\subsection{Isolation and Identification of Invertebrate Symbionts}

After sampling, invertebrates were transferred carefully to the laboratory to be processed. Small pieces of tissue were taken from the samples before frozen. Invertebrate samples $\left(1 \mathrm{~cm}^{3}\right)$ were ground in sterile seawater and heated at $50^{\circ} \mathrm{C}$ for $1 \mathrm{~h}$. The suspension was serially diluted, plated on Difco ${ }^{\mathrm{TM}}$ Marine Broth Agar (BD Biosciences San Jose, CA, USA), and incubated at $28^{\circ} \mathrm{C}$ for six weeks. A single colony was picked from the agar and cultivated as a pure culture on Difco ${ }^{\mathrm{TM}}$ Potato Dextrose Agar and Difco ${ }^{\mathrm{TM}}$ Marine Broth Agar (BD Biosciences San Jose, CA, USA) (media and cultivated for five days at $28^{\circ} \mathrm{C}$. The strain spores and mycelium were recovered by a gentle scratch of the agar plate surface using a scalpel, and they were conserved at $-20^{\circ} \mathrm{C}$ in $10 \%$ glycerol solution.

Genomic DNA of the purified strains was isolated using a DNeasy Plant Mini Kit (Qiagen, Hilden, Germany), according to the manufacturer's instructions. The ITS region was amplified with primers ITS1F (5'-CTTGGTCATTTAGAGGAAGTAA-3') and ITS4 (5'-TCCTCCGCTTATTGATATGC- $3^{\prime}$ ) using described polymerase chain reaction (PCR) conditions. Amplicons were sequenced by Sanger sequencing (GATC, Eurofins Genomics, Ebersberg, Germany), and the sequences were aligned against the non-redundant database of NCBI using the BLASTn program.

\subsection{Culture Conditions and Resting-Cell Reactions}

The culture procedure followed was the same as previously reported [11]. Fungal strains were grown on Difco ${ }^{\mathrm{TM}}$ Marine Agar 2216 (BD Biosciences San Jose, CA, USA) plates containing $100 \mu \mathrm{g} \cdot \mathrm{mL}^{-1}$ Ampicillin at $27^{\circ} \mathrm{C}$ for five days. Mycelia from these were used to inoculate submerged cultures with Difco ${ }^{\mathrm{TM}}$ Marine Broth 2216 (BD Biosciences San Jose, CA, USA) (pH 7.6) at $27^{\circ} \mathrm{C}$ and $160 \mathrm{rpm}$. After five days, the biomass was filtered using 0.2 - $\mu \mathrm{m}$-pore Supor ${ }^{\circledR}$ polyethersulfone (PES) membrane disc filters (Pall Corporation, Port Washington, NY, USA) and used as a biocatalyst (10\% w/v) in 15-mL reactions containing $1 \mathrm{mM}$ 2,4-DCP in ultrapure water. Reactions with just 2,4-DCP were used as controls for the abiotic transformations. Furthermore, for each strain, control reactions with the same amount of biomass but no addition of 2,4-DCP were also realized. All reactions were left at $27^{\circ} \mathrm{C}$ and $120 \mathrm{rpm}$ for 10 days. Samples were withdrawn on the third and sixth days and analyzed after filtration. On the final day, the remaining reaction was extracted with equal volume of chloroform, and it was analyzed after drying and resolubilization in ultrapure water.

\subsection{Detection and Quantification of 2,4-DCP}

The quantification of 2,4-DCP was performed using the same method, as previously reported [11] using a SHIMADZU LC-20AD HPLC equipped with a SIL-20A autosampler (Kyoto, Japan). A C-18 reverse-phase NUCLEOSIL ${ }^{\circledR} 100-5$ (Macherey-Nagel, Dueren, Germany) served as the stationary phase and $40 \%$ aqueous acetonitrile served as the mobile phase at a flow rate of $0.8 \mathrm{~mL} \cdot \mathrm{min}^{-1}$. Detection took place with the photodiode array detector Varian ProStar (Varian Inc., Palo Alto, CA, USA) at $285 \mathrm{~nm}$. The total running time was $16 \mathrm{~min}$ and the retention time of 2,4-DCP was $12.4 \mathrm{~min}$.

\subsection{Identification of 2,4-DCP Metabolites by LC-MS}

The analysis was performed on an ESI-LTQ-Orbitrap Discovery XL mass spectrometer (Thermo Scientific, San Jose, CA, USA) connected to an Accela UHPLC system (Thermo Scientific, San Jose, CA, USA). A Fortis UPLC C18 $(2.1 \times 100 \mathrm{~mm}, 1.7 \mu \mathrm{m})$ reverse-phase column (Fortis Technologies Ltd., Neston, UK) was used for the analysis. The mobile phase was a mixture of $0.1 \%(v / v)$ formic acid/water (solvent A) and acetonitrile (solvent B). Sample analysis was carried out in both positive (ESI+) and negative (ESI-) ion mode. The flow rate was $0.4 \mathrm{~mL} \cdot \mathrm{min}^{-1}$. A gradient method of $30 \mathrm{~min}$ was used for the analysis as follows: 0 to $24 \mathrm{~min}: 95 \% \mathrm{~A}, 5 \% \mathrm{~B} ; 24$ to $28 \mathrm{~min}$ : 5\% A, 95\% B; 28 to $30 \mathrm{~min}: 95 \% \mathrm{~A}, 5 \% \mathrm{~B}$. The column temperature was maintained at $40{ }^{\circ} \mathrm{C}$ and the injection volume was $10 \mu \mathrm{L}$. The conditions for the HRMS in each ionization mode were set as follows: for the positive ion mode, the capillary temperature and voltage were set at $320^{\circ} \mathrm{C}$ and $40 \mathrm{~V}$, respectively. The sheath gas 
flow was set to 40, and the aux gas flow was set to 8 arb units. The spray voltage was set to $3.6 \mathrm{kV}$, and the tube lens voltage was set to $120 \mathrm{~V}$. For the negative ion mode, the capillary temperature and voltage were set to $320^{\circ} \mathrm{C}$ and $-20 \mathrm{~V}$, respectively. The sheath gas flow was set to 40 , and the aux gas flow was set to 8 arb units. The spray voltage was set to $2.7 \mathrm{kV}$, and tube lens voltage was set to $-80 \mathrm{~V}$. In both positive and negative ion mode, analysis was performed using the Fourier-transform mass spectrometer (FTMS) (Thermo Scientific, San Jose, CA, USA) full-scan ion mode. The Orbitrap resolution was set to 30,000 full width at half maximum (FWHM) and the data-dependent acquisition mode of the three most intense ions was used for studying the MS/MS fragmentation pattern in parallel to the acquisition of full-scan mass spectra. Data acquisition was performed for a mass range of 100-1000 Da, and the spectra were acquired in the centroid mode.

\subsection{Measurement of Enzymatic Activities}

Induction of enzymatic activities began by introduction of $1 \mathrm{mM} 2,4-\mathrm{DCP}$ (final concentration) in 50-mL fungal cultures that were left to grow for three days as mentioned above. Samples were withdrawn at frequent intervals and centrifuged at $14,000 \times g$ for $10 \mathrm{~min}\left(10^{\circ} \mathrm{C}\right)$ to remove the biomass. The supernatant was used as crude extracellular enzyme for the detection of catechol dioxygenase activities. After the last sample was taken, the remaining biomass was lysed in order to measure intracellular enzymatic activities. Lysis was initiated by adding 670 units of Lyticase (\#L4025; Sigma-Aldrich, St. Louis, MO, USA) per gram of biomass in $0.1 \mathrm{M}$ potassium phosphate buffer $\mathrm{pH}$ 7.5 and left to incubate at $30^{\circ} \mathrm{C}$ for $1 \mathrm{~h}$. Afterward, $10 \mathrm{~mL}$ of the same buffer with $1.2 \mathrm{M}$ sorbitol and $0.5 \mathrm{mM} \mathrm{MgCl}_{2}$ was added to the reaction. The biomass suspension was sonicated at $4{ }^{\circ} \mathrm{C}$ in a VC505 Vibra-Cell Processor (Sonics \& Materials Inc., Newtown, CT, USA) for four cycles of sonication (1 min of 8-s pulse followed by 8-s pause). The resulting suspension was centrifuged for $20 \mathrm{~min}$ at $20,000 \times g$ $\left(4{ }^{\circ} \mathrm{C}\right)$, and the resulting supernatant was used as intracellular crude enzyme for enzymatic assays.

A typical assay ( $250 \mu \mathrm{L}$ final volume) contained $1 \mathrm{mM}$ catechol as substrate in $50 \mathrm{mM}$ Tris- $\mathrm{HCl}$ $\mathrm{pH} 7$ buffer. The reaction began with the addition of $25 \mu \mathrm{L}$ of crude enzyme and its time-course was recorded on a SpectraMax-250 microplate reader (Molecular Devices, Sunnyvale, CA, USA) equipped with SoftMaxPro software (version 1.1, Molecular Devices, Sunnyvale, CA, USA) set at $35^{\circ} \mathrm{C}$. One unit $(\mathrm{U})$ of catechol 1,2-dioxygenase $(\mathrm{C} 12 \mathrm{O})$ activity is defined as the amount of enzyme that produces $1 \mu \mathrm{mol}$ cis,cis-muconic acid per minute under the assay conditions. One unit (U) of catechol 2,3-dioxygenase (C23O) activity is defined as the amount of enzyme that produces $1 \mu \mathrm{mol}$ 2-hydroxymuconic semialdehyde per minute under the assay conditions. The products of $\mathrm{C} 12 \mathrm{O}$ and $\mathrm{C} 23 \mathrm{O}$ were detected at $260 \mathrm{~nm}$ and $375 \mathrm{~nm}$, respectively, and they were quantified according to Lin and Milase [18] and Hupert-Kocurek et al. [31].

\section{Conclusions}

The present work aimed towards the expansion of the biocatalytic toolbox for the bioremediation of chlorinated aromatic pollutants. Bioprospecting of novel microorganisms was achieved by accessing marine regions at various depths and collecting invertebrates. Fungal symbionts of these invertebrates were isolated, identified, and screened for their ability to transform high 2,4-DCP concentrations. The most competent strains were studied further in order to elucidate the mechanisms which they use in order to cope with this chlorinated pollutant. Since these strains originate from pristine habitats, their enzymatic arsenal is not evolved specifically for the biotransformation of this xenobiotic. In fact, these strains seemed to employ non-specific pathways, which nevertheless could lead to less toxic and, in some cases, fully dechlorinated metabolites. Surprisingly, one of the strains had the ability to cleave the aromatic structure of the pollutant following its dechlorination. This suggests the assimilation of the xenobiotic by this strain, which is the main objective of every bioremediation process. When tested for ring-cleavage activities, the same strain expressed the highest catechol dioxygenase activity, demonstrating the key enzyme for efficient bioremediation. 2,4-DCP can be considered as a model chlorinated aromatic pollutant, and strains with the ability to detoxify this compound are 
candidates for the bioremediation of other chlorinated xenobiotics. In our following studies, we will focus on the complete elucidation of the detoxification mechanism of chlorinated pollutants by these fungal strains using transcriptomic and genomic analyses [32].

Author Contributions: E.T., N.F., and J.O. conceptualized the investigation; E.N. and A.A. performed biocatalysis experiments; G.L.G. isolated and identified symbionts; E.B. and N.T. performed metabolite analysis; S.A.C. and Y.B. collected invertebrates; E.N. wrote the paper; E.T. supervised the project. All authors have read and agreed to the published version of the manuscript.

Funding: This study was supported by TASCMAR, a project funded by the European Union's Horizon 2020 research and innovation program under grant agreement no. 634674. This research was co-financed by Greece and the European Union (European Social Fund-ESF) through the Operational Program "Human Resources Development, Education, and Lifelong Learning" in the context of the project "Strengthening Human Resources Research Potential via Doctorate Research" (MIS-5000432), implemented by the State Scholarships Foundation (IK $\Upsilon$ ).

Acknowledgments: Yehuda Benayahu would like to thank the Interuniversity Institute for Marine Sciences in Eilat (IUI) for the use of the Sam Rothberg R/V and the professional assistance of its crew members. We are indebted to EcoOcean staff members for operating the ROV. We acknowledge Michal Weis and Ronen Liberman and Erez Shoham for help in the field work and Alex Shlagman for curatorial skills. Collection of invertebrates in Eilat (northern Red Sea) and in the Israeli Mediterranean coast complied with a permit issued by the Israel Nature and National Parks Protection Authority.

Conflicts of Interest: The authors declare no conflicts of interest.

\section{References}

1. Dhir, B. Bioremediation technologies for the removal of pollutants. In Advances in Environmental Biotechnology; Kumar, R., Sharma, A.K., Ahluwalia, S.S., Eds.; Springer: Singapore, 2017; pp. 69-91. ISBN 978-981-10-4041-2.

2. Kalogerakis, N.; Arff, J.; Banat, I.M.; Broch, O.J.; Daffonchio, D.; Edvardsen, T.; Eguiraun, H.; Giuliano, L.; Handå, A.; López-de-Ipiña, K.; et al. The role of environmental biotechnology in exploring, exploiting, monitoring, preserving, protecting and decontaminating the marine environment. N. Biotechnol. 2015, 32, 157-167. [CrossRef]

3. Gul, R.; Kumar, R. Introduction to Environmental Biotechnology. In Advances in Environmental Biotechnology; Kumar, R., Anil Kumar, S., Sarabjeet Singh, A., Eds.; Springer: Singapore, 2017; pp. 1-11.

4. Arora, P.K.; Srivastava, A.; Singh, V.P. Application of monooxygenases in dehalogenation, desulphurization, denitrification and hydroxylation of aromatic compounds. J. Bioremediat. Biodegrad. 2010. [CrossRef]

5. Guzik, U.; Hupert-Kocurek, K.; Wojcieszysk, D. Intradiol dioxygenases-The key enzymes in xenobiotics degradation. In Biodegradation of Hazardous and Special Products; Chamy, R., Rosenkranz, F., Eds.; InTech: Vienna, Austria, 2013; pp. 129-153. ISBN 978-953-51-1155-9.

6. Siegbahn, P.E.M.; Haeffner, F. Mechanism for catechol ring-cleavage by non-heme iron extradiol dioxygenases. J. Am. Chem. Soc. 2004, 126, 8919-8932. [CrossRef]

7. Fetzner, S. Ring-cleaving dioxygenases with a cupin fold. Appl. Environ. Microbiol. 2012, 78, 2505-2514. [CrossRef] [PubMed]

8. Nikolaivits, E.; Dimarogona, M.; Fokialakis, N.; Topakas, E. Marine-derived biocatalysts: Importance, accessing and application in aromatic pollutant bioremediation. Front. Microbiol. 2017, 8, 265. [CrossRef] [PubMed]

9. Atashgahi, S.; Häggblom, M.M.; Smidt, H. Organohalide respiration in pristine environments: Implications for the natural halogen cycle. Environ. Microbiol. 2018, 20, 934-948. [CrossRef]

10. Kumari, M.; Ghosh, P.; Thakur, I.S. Application of microbes in remediation of hazardous wastes: A review. In Bioremediation: Applications for Environmental Protection and Management. Energy, Environment, and Sustainability; Varjani, S., Agarwal, A., Gnansounou, E.G.B., Eds.; Springer: Singapore, 2018; pp. $223-241$. ISBN 978-981-10-7485-1.

11. Nikolaivits, E.; Agrafiotis, A.; Termentzi, A.; Machera, K.; Le Goff, G.; Álvarez, P.; Chavanich, S.; Benayahu, Y.; Ouazzani, J.; Fokialakis, N.; et al. Unraveling the detoxification mechanism of 2,4-dichlorophenol by marine-derived mesophotic symbiotic fungi isolated from marine invertebrates. Mar. Drugs 2019, 17, 564. [CrossRef] [PubMed] 
12. Vroumsia, T.; Steiman, R.; Seigle-Murandi, F.; Benoit-Guyod, J.-L. Groupe pour l'Étude du Devenir des Xénobiotiques dans l'Environnement (GEDEXE) Fungal bioconversion of 2,4-dichlorophenoxyacetic acid (2,4-D) and 2,4-dichlorophenol (2,4-DCP). Chemosphere 2005, 60, 1471-1480. [CrossRef] [PubMed]

13. Matafonova, G.; Shirapova, G.; Zimmer, C.; Giffhorn, F.; Batoev, V.; Kohring, G.-W. Degradation of 2,4-dichlorophenol by Bacillus sp. isolated from an aeration pond in the Baikalsk pulp and paper mill (Russia). Int. Biodeterior. Biodegrad. 2006, 58, 209-212. [CrossRef]

14. Kargi, F.; Eker, S. Kinetics of 2,4-dichlorophenol degradation by Pseudomonas putida CP1 in batch culture. Int. Biodeterior. Biodegrad. 2005, 55, 25-28. [CrossRef]

15. Chen, A.; Zeng, G.; Chen, G.; Fan, J.; Zou, Z.; Li, H.; Hu, X.; Long, F. Simultaneous cadmium removal and 2,4-dichlorophenol degradation from aqueous solutions by Phanerochaete chrysosporium. Appl. Microbiol. Biotechnol. 2011, 91, 811-821. [CrossRef] [PubMed]

16. Stoilova, I.; Krastanov, A.; Stanchev, V.; Daniel, D.; Gerginova, M.; Alexieva, Z. Biodegradation of high amounts of phenol, catechol, 2,4-dichlorophenol and 2,6-dimethoxyphenol by Aspergillus awamori cells. Enzyme Microb. Technol. 2006, 39, 1036-1041. [CrossRef]

17. Subbotina, N.M.; Kolomytseva, M.P.; Baskunov, B.P.; Golovlev, L.A. Catechol 1,2-dioxygenase induced in Rhodococcus opacus strain 1CP cultured in the presence of 3-hydroxybenzoate. Microbiology 2016, 85, 638-641. [CrossRef]

18. Lin, J.; Milase, R.N. Purification and characterization of catechol 1,2-dioxygenase from Acinetobacter sp. Y64 strain and Escherichia coli transformants. Protein J. 2015, 34, 421-433. [CrossRef] [PubMed]

19. Guzik, U.; Hupert-Kocurek, K.; Sitnik, M.; Wojcieszyńska, D. High activity catechol 1,2-dioxygenase from Stenotrophomonas maltophilia strain $\mathrm{KB} 2$ as a useful tool in cis,cis-muconic acid production. Antonie Leeuwenhoek Int. J. Gen. Mol. Microbiol. 2013, 103, 1297-1307. [CrossRef] [PubMed]

20. Giedraityte, G.; Kalèdienè, L. Catechol 1,2-dioxygenase from $\alpha$-naphthol degrading thermophilic Geobacillus sp. strain: Purification and properties. Open Life Sci. 2009, 4, 68-73. [CrossRef]

21. Santos, V.L.; Linardi, V.R. Biodegradation of phenol by a filamentous fungi isolated from industrial effluents-identification and degradation potential. Process Biochem. 2004, 39, 1001-1006. [CrossRef]

22. Cai, W.; Li, J.; Zhang, Z. The characteristics and mechanisms of phenol biodegradation by Fusarium sp. J. Hazard. Mater. 2007, 148, 38-42. [CrossRef]

23. Tsai, S.-C.; Li, Y.-K. Purification and characterization of a catechol 1,2-dioxygenase from a phenol degrading Candida albicans TL3. Arch. Microbiol. 2007, 187, 199-206. [CrossRef]

24. Long, Y.; Yang, S.; Xie, Z.; Cheng, L. Cloning, expression, and characterization of catechol 1,2-dioxygenase from a phenol-degrading Candida tropicalis JH8 strain. Prep. Biochem. Biotechnol. 2016, 46, 673-678. [CrossRef]

25. El-Naas, M.H.; Mousa, H.A.; Gamal, M. El Microbial degradation of chlorophenols. In Microbe-Induced Degradation of Pesticides; Singh, S.N., Ed.; Springer: New York, NY, USA, 2017; pp. 23-58.

26. Marco-Urrea, E.; Reddy, C.A. Degradation of chloro-organic pollutants by white rot fungi. In Microbial Degradation of Xenobiotics. Environmental Science and Engineering; Singh, S., Ed.; Springer: Berlin/Heidelberg, Germany, 2012; pp. 31-66. ISBN 978-3-642-23789-8.

27. Aranda, E. Promising approaches towards biotransformation of polycyclic aromatic hydrocarbons with Ascomycota fungi. Curr. Opin. Biotechnol. 2016, 38, 1-8. [CrossRef] [PubMed]

28. Nakagawa, A.; Osawa, S.; Hirata, T.; Yamagishi, Y.; Hosoda, J.; Horikoshi, T. 2,4-Dichlorophenol degradation by the soil fungus Mortierella sp. Biosci. Biotechnol. Biochem. 2006, 70, 525-527. [CrossRef]

29. Arora, P.; Bae, H. Bacterial degradation of chlorophenols and their derivatives. Microb. Cell Fact. 2014, 13, 31. [CrossRef]

30. Rubilar, O.; Diez, M.C.; Gianfreda, L. Transformation of chlorinated phenolic compounds by white rot fungi. Crit. Rev. Environ. Sci. Technol. 2008, 38, 227-268. [CrossRef] 
31. Hupert-Kocurek, K.; Wojcieszyfska, D.; Guzik, U.; Borowski, T.; Wojcieszyńska, D.; Guzik, U.; Borowski, T. A single amino acid substitution within catalytically non-active N-terminal domain of catechol 2,3-dioxygenase (C23O) increases enzyme activity towards 4-chlorocatechol. J. Mol. Catal. B Enzym. 2015, 122, 64-71. [CrossRef]

32. Gioti, A.; Siaperas, R.; Nikolaivits, E.; Le Goff, G.; Ouazzani, J.; Kotoulas, G.; Topakas, E. Draft genome sequence of a Cladosporium species isolated from the mesophotic ascidian Didemnum maculosum. Microbiol. Resour. Announc. 2020, 9. [CrossRef] [PubMed]

(C) 2020 by the authors. Licensee MDPI, Basel, Switzerland. This article is an open access article distributed under the terms and conditions of the Creative Commons Attribution (CC BY) license (http://creativecommons.org/licenses/by/4.0/). 